\title{
Wind waves in the North Atlantic from ship navigational radar: SeaVision development and its validation with Spotter wave buoy and WaveWatch III
}

5 Natalia Tilinina ${ }^{1,2}$, Dmitry Ivonin ${ }^{1}$, Alexander Gavrikov ${ }^{1}$, Vitaly Sharmar ${ }^{1}$, Sergey Gulev ${ }^{1,3}$, Alexander Suslov ${ }^{1}$, Vladimir Fadeev ${ }^{4}$, Boris Trofimov ${ }^{4}$, Sergey Bargman ${ }^{4}$, Leysan Salavatova ${ }^{5}$, Vasilisa Koshkina ${ }^{5}$, Polina Shishkova ${ }^{1}$, Olga Razorenova $^{1}$ and Alexey Sokov ${ }^{1}$

${ }^{1}$ Shirshov Institute of Oceanology, RAS, Nakhimovsky ave. 36, 117997, Moscow, Russia

$10 \quad{ }^{2}$ Université Grenoble Alpes, IGE, 70 rue de la Physique, 38400, Grenoble, France

${ }^{3}$ A.M. Obukhov Institute of Atmospheric Physics, RAS, 3, Pyzhevskiy Lane, Moscow, 109017, Russia

${ }^{4}$ Joint stock company "Marine Complexes and Systems", 13th line of Vasilyevsky Island, 199034, Saint Petersburg, Russia.

${ }^{5}$ Moscow Institute of Physics and Technology, Institutskiy Pereulok 9, 141701, Dolgoprudny, Moscow Region, Russia

Correspondence to: Natalia Tilinina (tilinina@sail.msk.ru) and Alexander Gavrikov (gavr@sail.msk.ru)

\section{Abstract}

The global coverage of the observational network of the wind waves is still characterized by the significant gaps in in situ observations. At the same time wind waves play an important role into the Earth' climate system specifically in the air-sea interaction processes and energy exchange between the ocean and the atmosphere. In this paper we present the SeaVision system for measuring wind waves' parameters in the open ocean with navigational marine X-band radar and prime data collection from the three research cruises in the North Atlantic (2020 and 2021) and Arctic (2021). Simultaneously with SeaVision observations of the wind waves we were collecting data in the same locations and time with Spotter wave buoy and running WaveWatch III model over our domains. Measurements with SeaVision were quality controlled and validated by comparison with Spotter buoy data and WaveWatch III experiments. Observations of the wind waves with navigational Xband radar are in agreement among these three sources of data, with the best agreement for wave propagation directions. The

25 dataset that supports this paper consists of significant wave height, wave period and wave energy frequency spectrum from both SeaVision and Spotter buoy. Currently the dataset is available through the temporary link (https://sail.ocean.ru/tilinina2021/) while supporting dataset (Tilinina et al., 2021) is in technical processing at PANGAEA repository. The dataset can be used for validation of satellite missions as well as model outputs. One of the major highlights in this study is potential of all ships navigating into the open ocean and equipped with $\mathrm{X}$-band marine radar to participate into

30 the development of another observational network for the wind waves in the open ocean once cheap and independently operating version of the SeaVision (or any other system) is available. 
https://doi.org/10.5194/essd-2021-431

Preprint. Discussion started: 16 December 2021

(c) Author(s) 2021. CC BY 4.0 License.

\section{Introduction}

The history of wind waves studies in the ocean demonstrated a critically important role of the wind waves into the climate system, specifically in air-sea interaction processes and energy exchange between the ocean and the atmosphere. At the same time, the history of building a robust global and regional datasets for assessment of the wind waves climatology and dynamics revealed that the wave fields are always hard to measure both remotely and in situ with sufficient temporal and spatial resolutions to cover global and regional domains (comparing with e.g. air temperature or sea surface temperature).

Regular observations of the wind waves date back to the 19th century when the Voluntary Observing Ships (VOS) reported first visual observations of wind waves in the open ocean. However, the VOS dataset is characterized by sparse spatial and

40 temporal resolutions and by the bias of the individual observers - marine officers.

Remote sensing datasets of the wind waves are dating back to 1985 (Ribal and Young, 2019), when the first satellite radar altimeters missions began measurements of the elevations of the ocean surface, providing better temporal and spatial cover of wind waves fields. At the same time remote sensing has to be validated with in situ measurements, typically buoys that are deployed in coastal regions (such as NDBC buoys, Swail et al. 2010 or NOWPHAS, Nagai et al. 2005). Buoys are measuring

45 vertical and horizontal displacements of the ocean surface (such as Spotter or Datawell buoys with up to $2.5 \mathrm{~Hz}$ sampling frequency, Raghukumar et al., 2019) and are the most precise and effective way to estimate wind waves characteristics, providing accurate inputs for the data assimilation in Numerical Weather Prediction (NWP) models and theoretical studies. Being very important and accurate data providers, buoys cover only a few locations and rather can be used as "ground truth" for verification of all other dataset.

50 Significant improvement of the global picture of the wind waves is dating back to 1988 when the obvious relation between the wind and waves was implemented in spectral wave models as Discrete Interaction Approximation (DIA) parametrization (WAMDI, 1988; Hasselman et al., 1985; Cavaleri et al., 2020), while first relations between wind and waves were quantified by (Sverdrup and Munk, 1947). Nowadays wave modelling is suffering from the lack of accuracy for modelling and prediction of extremely high wave peaks during high wind speeds (e.g. during the storm passage, Cavaleri et al., 2020).

55 An important operational task is delivery of the wave forecast to the ships in the open ocean, which is typically (i) not very operational and (ii) not very accurate during the rough sea conditions. Thus, within this paper we present results of development and validation of the SeaVision system for (i) collecting wind waves observations in the open ocean using navigational marine $\mathrm{X}$-band radar and (ii) to monitor in real time wave heights, direction and period along the ship track in the open ocean.

The methodology of the navigational marine radar adaptation for measurements of the wind waves characteristics was 60 announced by (Young et al., 1985). The radar images of the ocean surface, known as sea clutter, are generated by the Bragg scattering (Crombie, 1955) of the electromagnetic signal by the ripples on the ocean surface produced by the wind. Being emitted from the radar, an electromagnetic signal reaches the ocean surface and further, being reflected by ripples on the ocean surface, received back by the radar antenna when the ocean surface is rough enough (i.e. ripples are developed). Under conditions of the wind speed $>3 \mathrm{~m} / \mathrm{s}$ and waves height $>0.5 \mathrm{~m}$ waves field becomes visible on the radar image of the sea 
https://doi.org/10.5194/essd-2021-431

Preprint. Discussion started: 16 December 2021

(c) Author(s) 2021. CC BY 4.0 License.

65 clutter (Hatten et al., 1998; Hessner and Hanson, 2010). Time sequences of these images are further analyzed in space and time for estimation of wind waves' characteristics. Using various approaches: signal-to-noise ratio derived from the image spectrum (Nieto-Borge et al., 1999; Neito-Borge et al., 2008; Seemann et al., 1997), statistical analysis of island-to-trough ratio on the sea clutter images (Buckley and Alter, 1997; Buckley and Alter, 1998), analysis of the images' texture (Gangeskar, 2000), wavelet technique (Huang and Gill, 2015), the least square approach (Huang et al., 2014) and shadowing analysis

70 (Gangeskar, 2014; Liu et al., 2015), or combination of these methods with usage of artificial neural networks (Vicen-Bueno et al., 2012), analysis of the Doppler shift of the received radar signal because of the well-defined relationship between orbital velocities and wave height for linear gravity waves (Plant, 1997; Plant et al., 1987; Johnson et al., 2009; Hwang et al., 2010; Hackett et al., 2011; Chen et al., 2019). There are many aspects of the sea clutter radar images analysis, for example (Nieto Borge and Guedes Soares, 2000) proposed an approach for analysis of the sea states consisting of superpositions of swell and

75 wind sea components, that allows to derive wind waves and swell contributions to the total wave field, together with directional characteristic of the wave field.

There are also examples and techniques for using images of the sea clutter from X-band radars for estimation of the currentdepth profiles with Eulerian approach (Campana et al., 2017), to retrieve wind speed and wind direction (Chen et al., 2015; Dankert and Horstmann, 2007; Dankert et al., 2003; Vicen-Bueno et al., 2013), to determine snapshots of the currents at the 80 ocean surface (Senet et al., 2001).

On the basis of these studies and methods a series of commercial oceanographic systems such as WaMoS II (http://www.oceanwaves.de), SeaDarQ (Greenwood et al., 2018) and WaveFinder (Park et al., 2006) were developed. The most widely used system nowadays is WaMoS II (software, hardware and details provided in Reichert at al., 1999) focusing on operational monitoring of the sea state (wind waves and surface currents) and operational management of the oil platforms

85 and ships using nautical X-band radar. In combination with other sources of the data (e.g., altimetric wave radar, vessel hydrodynamic simulator) wind waves estimates from navigational radar can be used in maritime security, for example for the assessment of the ships fatigue due to mechanical environmental influence (Drouet et al., 2013) or for the real-time prediction of the ship motions (Hilmer and Thornhill, 2015).

In this study we present the SeaVision (Fig. 2) system for monitoring of the sea state with navigational marine radar and first 90 data that we collected during three research cruises (Fig. 1). SeaVision is an extension of the system for the sea ice monitoring with navigational marine radar - IceVision (https://ice.vision/en). SeaVision can be used for operational monitoring of the current wind waves' field for individual ships and continuous collection of the wind waves data for building new datasets of the wind waves characteristics in the open ocean. SeaVision was developed in collaboration between Shirshov Institute of Oceanology of the Russian Academy of Sciences (https://ocean.ru/, software for wind waves analysis, marine facilities, data

95 analysis and initiation of the project) and Joint stock company "Marine Complexes and Systems" ("MC\&S" J.S.C., https://www.mcs.ru/, hardware, radar signal digitization, data recording and storage). The first version of the SeaVision was tested and validated into two expeditions in the North Atlantic (2020 and 2021) and one expedition in the Arctic (2021, Fig. 1). The major advantage of the collected dataset is that together with collecting data from navigational radar in more than 50 
locations in the North Atlantic and Arctic (Fig. 1) we were using Spotter wave buoys simultaneously to directly measure characteristics of the wind waves in the same locations, we also run WaveWatch III (WW3DG) model forced by ERA5 reanalysis (Hersbach et al., 2020) for the period of the research cruises. We present in the study the SeaVision system and dataset of the measurements of the wind waves in the open ocean and its comprehensive analysis.

In the Section 2 we provide details of expeditions, technical details of the SeaVision and data collection and analysis principles together with an overview of the WW3 model setup. Section 3 contains analysis and validation of the SeaVision dataset with Spotter buoy and WW3 model output. Concluding remarks are made in the last section.

\section{Data collection and analysis principles}

\section{Expeditions}

Cruise 50 by RV Academic Sergey Vavilov (Aug 2020)

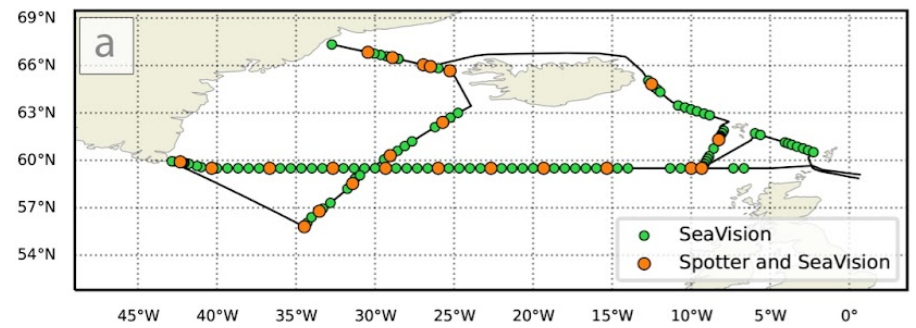

Cruise 57 by RV Academic loffe (Jul 2021)

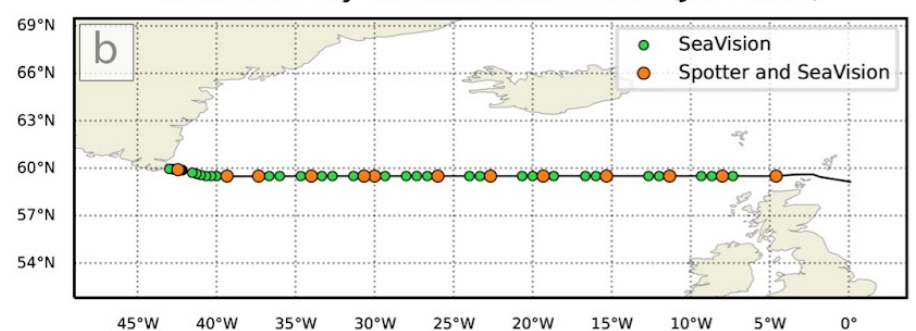

\section{Cruise 58 by RV Academic loffe (Aug 2021)}

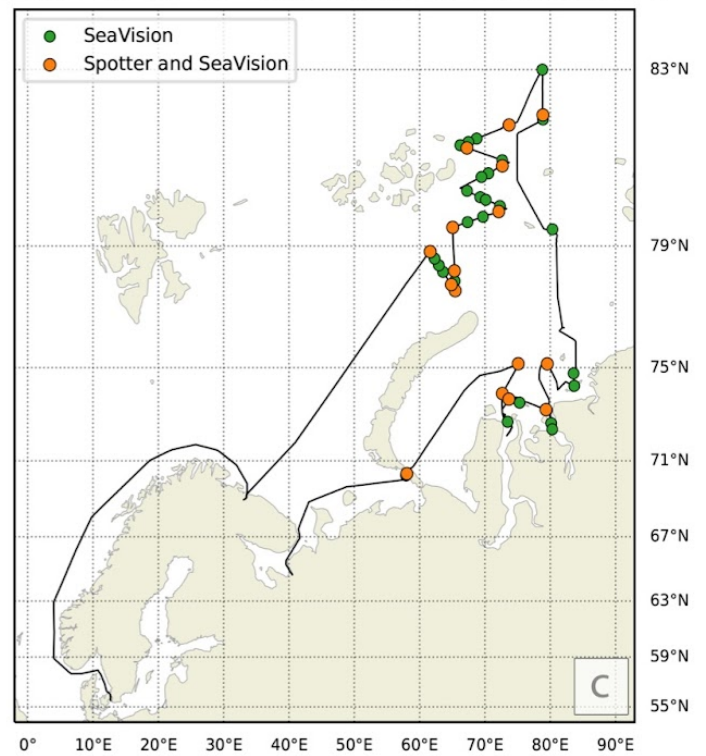

110 Figure 1: Pathways and dates of the three cruises of the research vessels Akademic Sergey Vavilov (a) and Akademik Ioffe (b,c). Green dots indicate locations where only SeaVision radar data was collected, orange dots correspond to simultaneous wind waves observations with Spotter wave buoy and SeaVision.

Figure 1 demonstrates pathways and dates of three research cruises, where the wind waves data were collected along with

115 other regular deep ocean observations. All three cruises were carried out by Shirshov Institute of Oceanology of the Russian Academy of Sciences (IO RAS) within the governmental program of regular ocean observations. In particular, two cruises in 
the North Atlantic (Figure 1a,b) are related to regular deep ocean observations at the 59,5N (Verezemskaya et al., 2021; Falina et al. 2007; Gladyshev et al. 2018, 2019; Sarafanov et al. 2008, 2018) and the Arctic expedition is a part of the IO RAS "Floating University of IORAS" program (Stepanova, 2018). In addition to the regular deep ocean observations in these cruises we were collecting data from navigational radar with the newly developed SeaVision system and simultaneously carrying out observations with Spotter buoy (https://www.sofarocean.com/products/spotter). During all "stations" research vessels were drifting during wave data collection (from 30 minutes to 2 hours) with its engines in neutral position to provide conditions for Spotter buoy wave observations in the free floating mode.

\section{SeaVision system}

\section{Radar signal preprocessing}

The first step before actual analysis of the images of the sea clutter is digitization of the radar signal and collection of the images' dataset. Research vessels Academic Sergey Vavilov (r/v ASV) and Akademik Ioffe (r/v AI) equipped with standardly operated X-band radar JRC JMA-9110-6XA and JMA-9122-6XA. Technical details of the radars transmission and reception characteristics are given in Table 1. Both radars have $9.41 \mathrm{GHz}$ frequency (radio wavelength $\sim 3 \mathrm{~cm}$ ), a 6 feet antenna with the horizontal directional resolution of $1.2^{\circ}$ (Table 1). Radars have the choice of the pulse lengths: $0.08 \mu \mathrm{s}, 0.25 \mu \mathrm{s}, 0.5 \mu \mathrm{s}, 0.8 \mu \mathrm{s}$, $1.0 \mu \mathrm{s}$. For our purposes we used the shortest possible pulse length of $0.08 \mu \mathrm{s}$ (at so-called "short-pulse" mode - SP1), that is equivalent to a $12 \mathrm{~m}$ angular spatial resolution.

SeaVision system (Fig. 2) connected to the radar via splitter, it digitizes and records directionally stabilized (northward) radar sea clutter images (converted to netcdf format during postprocessing) of each radar antenna rotation in digital format to the external storage, it is also connected to the ship's navigational equipment and records parameters such as: GPS geographical coordinates, speed of the ground (SOG), course of the ground (COG). Each antenna turn results in a separate ASCII file ( $16 \mathrm{MB}$ ) with the 4096x4096 matrix (1.875 m discretization at 4096 beam directions) with the sea clutter digitized 140 image, that contains GPS, SOG and COG in the header.

Table 1: JRC JMA-9110-6XA radar $(r / v A S V)$ and JMA-9122-6XA $(r / v A I)$ transmission and reception characteristics.

\begin{tabular}{|c|c|c|}
\hline Research vessel & $\begin{array}{c}\text { Akademik } \\
\text { Sergey Vavilov }\end{array}$ & $\begin{array}{c}\text { Akademik } \\
\text { Ioffe }\end{array}$ \\
\hline Radar type & JRC JMA-9110-6XA & JMA-9122-6XA \\
\hline Radar frequency/Wave length & & \\
& $9.41 \mathrm{Ghz} / 3.18 \mathrm{~cm}$ & $9.41 \mathrm{Ghz} / 3.18 \mathrm{~cm}$ \\
\hline
\end{tabular}




\begin{tabular}{|c|c|c|}
\hline Antenna rotation speed & $27 \mathrm{rpm}$ & $24 \mathrm{rpm}$ \\
\hline Impulse power & $10 \mathrm{~kW}$ & $25 \mathrm{~kW}$ \\
\hline Antenna size & $6 \mathrm{ft}$ & $6 \mathrm{ft}$ \\
\hline Pulse length mode & $0.08 \mu \mathrm{s}$ (short pulse) & $0.07 \mu$ s (short pulse) \\
\hline $\begin{array}{c}\text { Analog-digital converter (ADC) frequency/size of output matrix } \\
\text { for one antenna turn }\end{array}$ & $80 \mathrm{Mhz} / 4096 \mathrm{x} 4096$ & $80 \mathrm{Mhz} / 4096 \mathrm{x} 4096$ \\
\hline $\begin{array}{c}\text { Azimuthal coverage/resolution } \\
\text { Distance range }\end{array}$ & $0-360^{\circ} / 1.2^{\circ}$ & $0-360^{\circ} / 1.2^{\circ}$ \\
\hline Range resolution & $231,5-2778 \mathrm{~m}$ & $231,5-2778 \mathrm{~m}$ \\
\hline Analog-digital converter (ADC) \\
\hline frequency/size of output matrix for one antenna turn
\end{tabular}



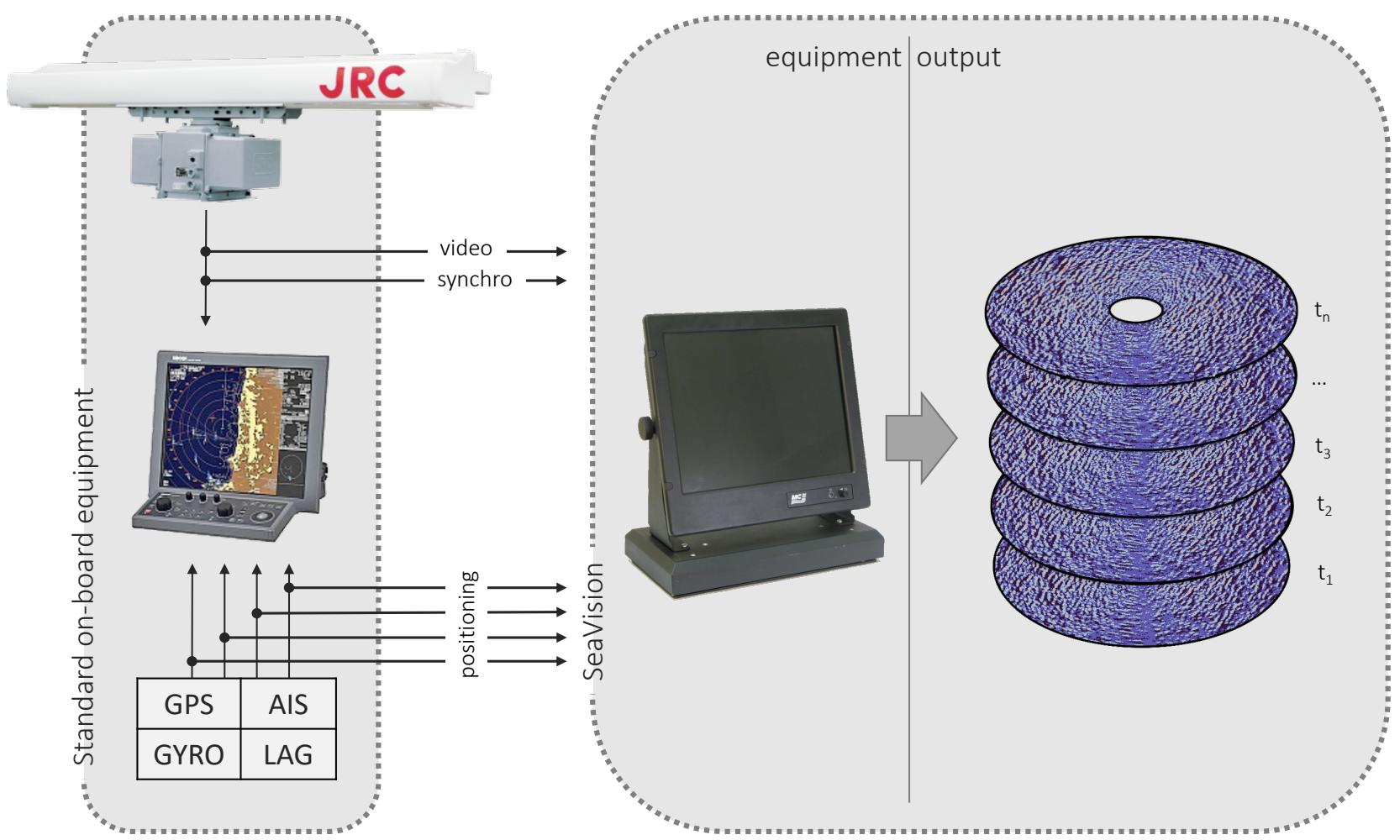

Figure 2: SeaVision integration to the ship's navigational equipment together with an example of the series of the geographically stabilized (northward) sea clutter images, one for each antenna turn (rightest column). Image of the JRC radar scanner (tor left) is taken from the www.jrc.co.jp.

\section{Analysis of the sea clutter images}

For every station (Fig.1) dataset consists of 20 minutes long observations with SeaVision, it is equivalent to a minimum 540 images of the sea clutter (27 antenna turns per minute for JRC JMA-9110-6XA radar) at one station.

Methodology for wind waves' characteristics estimates is a well established FFT-based technique (Nieto-Borge and Guedes

Soares, 2000; Borge et al., 2004, Borge et al., 2008 among others). For each station preprocessing of the data begins from the choice of the processing squared area (with a side of $720 \mathrm{~m}$ ). At this stage we locate the processing area by visual choice of the most apparent wave signal on the images and minimal distance from the ship of $300 \mathrm{~m}$ (to avoid potential impact of the ship to the wave field and illumination of the radar signal by the ship). After choosing the area we create the dataset for the further analysis by sampling the same squares from each image (one antenna turn). Data sampled in the polar coordinates were regridded to the Cartesian grid resulting in $384 \times 384$ pixels dataset array (with $1.875 \mathrm{~m}$ spatial resolution) for each station.

The sequence of these images is then transformed to the 3D spectral domain using fast Fourier transform (FFT, Fig. 3 , this results into the three-dimensional spectrum $S\left(k_{x}, k_{y}, f\right)$, where $f=\omega / 2 \pi$ is the frequency and $\omega$ is the angular 
frequency. Further we analyse resulting 3D spectra and extract the part of it that satisfies the linear dispersion relation for ocean waves (Fig. 3): $\Omega=\sqrt{g k \tanh (k H)}$, where $k$ is the wave number absolute value ( $\mathrm{rad} / \mathrm{m}), g$ is the gravity acceleration $\left(\mathrm{m}^{-1} \mathrm{~s}^{-1}\right.$ and $\mathrm{H}$ is significant wave height. Components of the spectra that lie outside of the dispersion relation are assumed to be noise or the signal $\left(\Omega_{B G N}\right)$, related to the other processes or speckle-noise (Kanevsky, 2008). These spectra estimates are calculated for 16 sectors (with $22.5^{\circ}$ width) to get the directional spectra estimates.

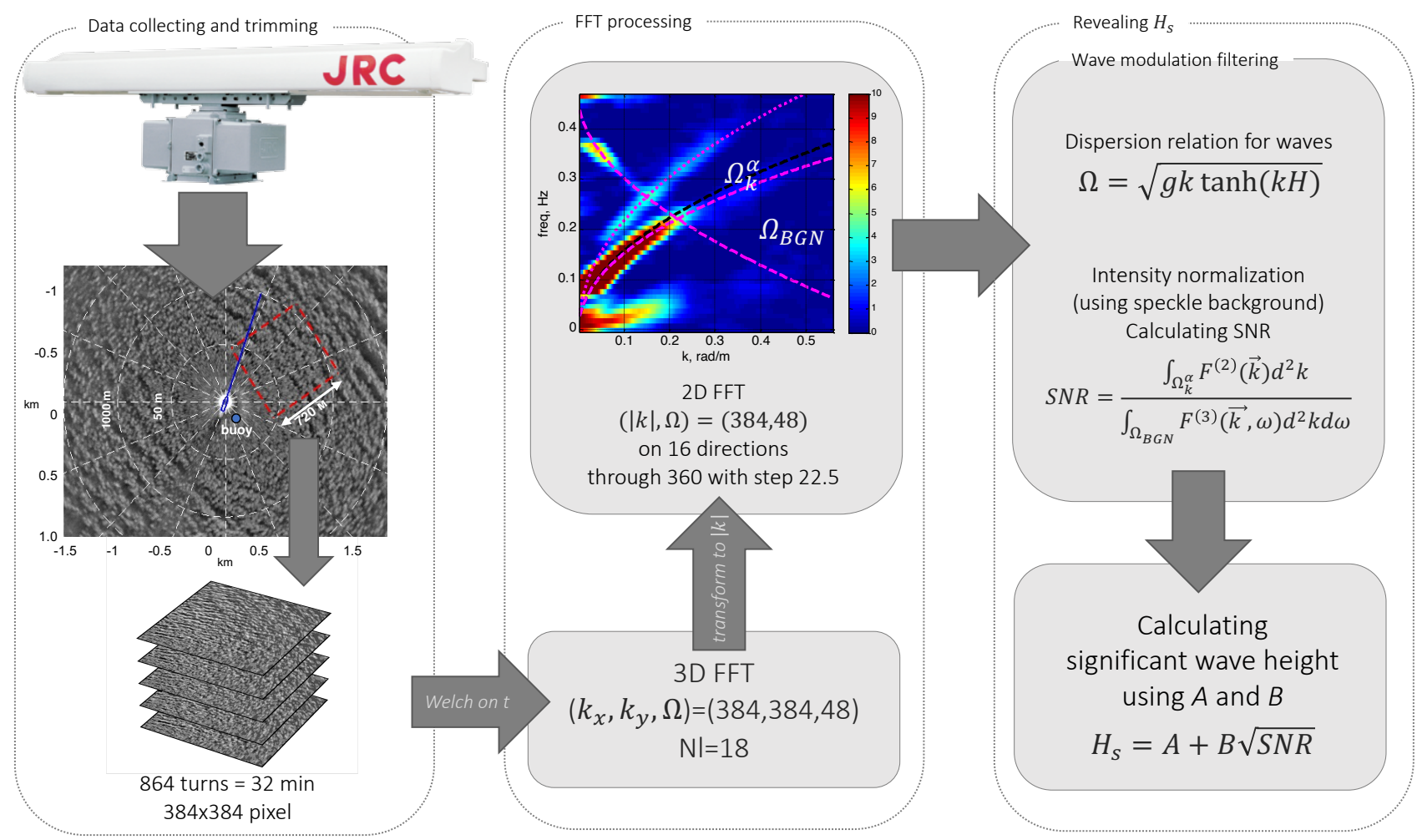

170 Figure 3: Data processing schematic for estimation of the wind waves parameters from the sea clutter images. Image of the JRC radar scanner (tor left) is taken from the www.jrc.co.jp.

According to (Nieto-Borge et al., 1999; Hessner et al., 2002; Young et al 1985, Nieto-Borge and Guedes Soares 2000, Ivonin et al. 2016 and others) estimates of the spectra from analysis of the raw radar images reflect spectrum of the radar backscatter rather than actual elevations of the ocean surface due to waves. To convert this spectra to estimates to the wind waves spectra we use a transfer function, so-called signal-to-noise $(S N R)$ ratio, where signal is the spectra power that satisfies dispersion relation (Fig. 3) and assumed to be due to the signal, modulated by wind waves, and noise is the remaining signal (spectral power) outside the dispersion relation. Then, according to (Nieto-Borge et al., 1999, 2004) $S N R$ can be converted to wave heights with linear regression equation: 
where $A$ and $B$ are empirical calibration coefficients individual for each radar. In this study calibration coefficients were calculated on the basis of the simultaneous observations with the Spotter wave buoy (see Section 2.3). Calibration coefficients are also used for calculation of the wave energy spectrum. We also use modulation transfer function (MTF, Nieto-Borge et al.,

185 2004) to correct radar antenna effects of tilting and shadowing to correct the wave energy spectral density. Finally, wave period $T_{s}$ estimated traditionally using the first moment of the spectrum.

\section{Spotter wave buoy data}

190 To calibrate and validate SeaVision waves observations we performed a series of simultaneous measurements of the wave parameters with Spotter wave buoy (https://www.sofarocean.com/products/spotter). Figure 1 demonstrates the track of the three cruises indicating locations where wind waves were measured simultaneously with Spotter wave buoy and SeaVision, Table A1 provides a list of all locations where SeaVision+Spotter buoy (or SeaVision only) measurements were carried out. Once the ship was in a drift at the location of the measurements according to the plan of the cruise, the Spotter buoy was

195 equipped, sent overboard and allowed to move away from the ship for at least $200 \mathrm{~m}$ (as the ship drift is faster than buoy drift due to the local winds, the distance between buoy and ship was constantly increasing). Starting from at least 200m separation the buoy was in a "free floating" mode recording horizontal and vertical displacements of itself. For each station we allowed for at least 20 minutes of the free floating buoy measurements, however at some stations this was up to 1.5 hours. For the homogeneity of the analysis for all stations we use 20-minute time series for wave parameters calculation.

200 Analysis of the raw vertical and horizontal displacements recorded by buoy starts from the selecting in timeseries the "free floating" measurements and further calculation of the significant wave height, wave spectra and directional moments (Fig. 4) using common definitions (see Appendix in Raghukumar et al., 2019), $H_{s}=4 \sqrt{E}$, where $E=\int_{0.05 \mathrm{~Hz}}^{0.3 \mathrm{~Hz}} E(f) d f-$ the surface elevations variance in the frequency range of the wind waves. More details on calculation of the mean wave direction, directional spread, wave directional spectrum and other parameters on the basis of the Spotter time series can be found in 205 (Raghukumar et al., 2019), together with evaluation of the buoy ability for wave characteristics measurements.

We further use wave parameters derived from buoy as the "ground truth" for the SeaVision calibration and estimation of the radar calibration coefficients $A$ and $B$, these coefficients are further used to rescale SeaVision wave energy spectrum to match buoy spectrum with least squares. 

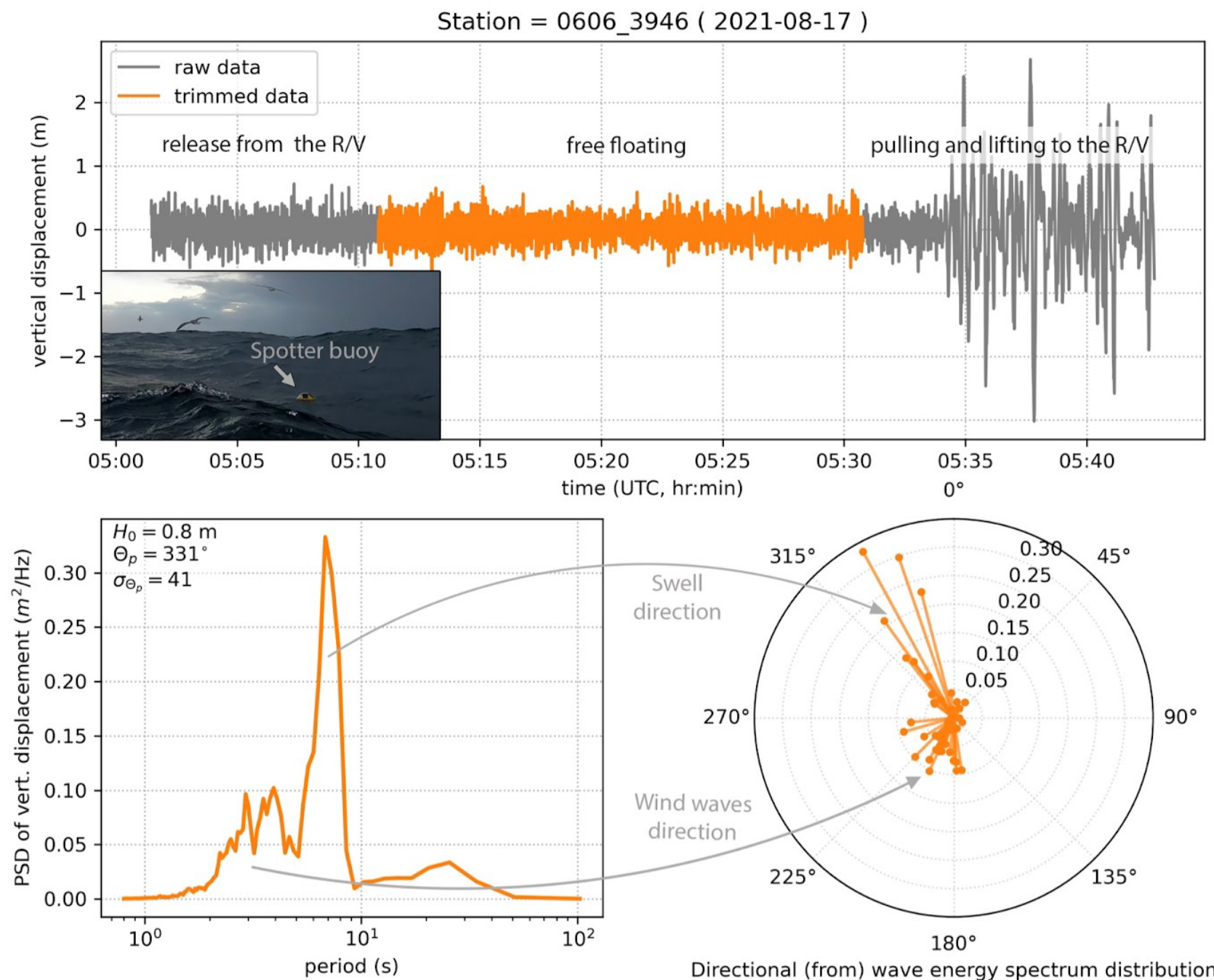

210 Figure 4: Spotter wave buoy timeseries of vertical displacements at the station \#3946 in the 58th cruise of R/V Academic Ioffe (top), wave energy spectrum together with significant wave height (bottom left) and directional wave spectrum (bottom right).

\section{Meteorological data}

Along all cruises the AIRMAR WeatherStation 220WX was mounted at the height of $30 \mathrm{~m}$ on the mainmast to avoid the impact of the ship on the local meteorology. Weather station provides standard output parameters: barometric pressure, wind speed 
and direction, air temperature and relative humidity. Wind characteristics were recalculated from apparent wind to true wind in real-time.

\section{WaveWatch III model experiment}

Another potential source of the wind waves data in the open ocean is spectral wave modelling. We run WaveWatch III (WW3DG, version 6.07, WW3) spectral wave model with ERA5 reanalysis (Hersbach et al., 2020) as lateral boundary conditions with $0.1^{\circ}$ spatial and 1 hourly temporal resolutions. The experiments have been developed to reconstruct twodimensional wave spectra comparable with SeaVision and Spotter buoy observations. Start and end dates of the experiments were collocated in time with dates of the research cruises. For wave energy input and dissipation we use ST6 parameterization (Bababin, 2006; Bababin, 2011; Rogers et al., 2012; Zieger et al., 2015) and the discrete interaction approximation (DIA) scheme for nonlinear wave interactions (Hasselmann and Hasselmann 1985).

\section{Validation and overall SeaVision performance}

Most of the analyses presented in this section are based on a common source location of surface wave observations from SeaVision, Spotter buoy and WW3 output information.

235 The overall agreement in significant wave height $\left(\mathrm{H}_{\mathrm{s}}\right)$ estimates is demonstrated in Fig. 5 where we plot difference in $\mathrm{H}_{\mathrm{s}}$ estimates: Spotter minus SeaVision (Fig. 5a) and Spotter minus WW3 (Fig, 5b) as a function of wind speed (wind speed recorded by the weather station) for all stations (Table A1). On average WW3 underestimates $\mathrm{H}_{\mathrm{s}}$ by $27 \mathrm{~cm}$, while SeaVision on average implies agreement with Spotter buoy data (only $3 \mathrm{~cm}$ difference on average). In general, for the lower wind speeds SeaVision underestimates $\mathrm{H}_{\mathrm{s}}$ by up to $50 \mathrm{~cm}$ and overestimates $\mathrm{H}_{\mathrm{s}}$ for the higher wind speeds. This effect can be due to better ripples development on the ocean surface during higher winds affecting the signal to noise ratio (Formula 1).
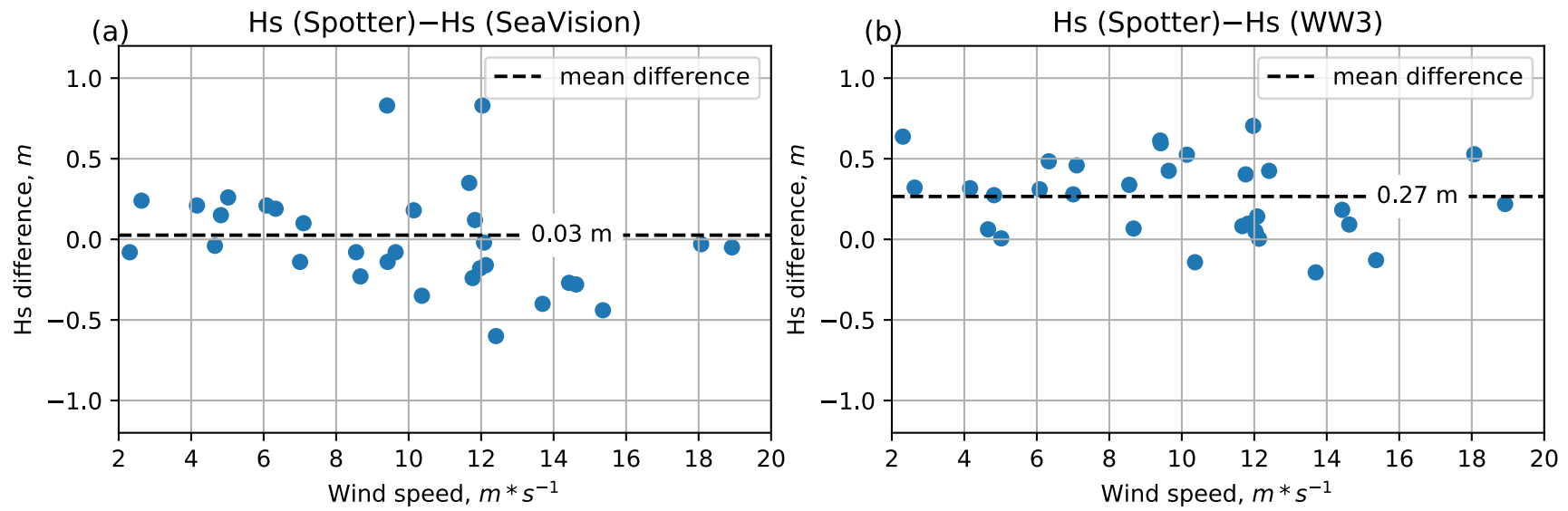
Figure 5: Difference in the significant wave height $\left(\mathrm{H}_{\mathrm{s}}\right)$ estimates for all stations as function of the wind speed: Spotter buoy ("ground truth") minus SeaVision (left panel), Spotter buoy minus WW3 (right panel). Dashed line marks mean difference among all stations.

At the same time there are two stations (2901 and 2937 see Table A1) where this difference reaches almost $100 \mathrm{~cm}$ (between 9 and $12 \mathrm{~m} / \mathrm{s}$ winds), examinations of weather conditions at these stations revealed that there were not any special weather conditions and observations were carried for $\mathrm{H}_{\mathrm{s}}$ between 1.5 and $2 \mathrm{~m}$, however there was a strong drift of the vessel due to the local current that potentially influenced the angles of electromagnetic signal reflection from the surface. Further examination and methodology adjustment required together with more data collection during different conditions in the open ocean are required to investigate into these differences.

Scatterplots for the $H_{s}$ and wave period $\left(T_{s}\right)$ also demonstrate better agreements between SeaVision and Spotter than between WW3 and Spotter (Fig. 6). Regression coefficients for SeaVision are 0.98 for $\mathrm{H}_{\mathrm{s}}$ and 0.9 for $\mathrm{T}_{\mathrm{s}}$ and only 0.88 and 0.63 for 255 WW3. There is also no evident dependance for $\mathrm{H}_{\mathrm{s}}$ and $\mathrm{T}_{\mathrm{s}}$ better or worser agreement between datasets from the amplitude of the $H_{s}$ and $T_{s}$ itself. Figure 6 illustrates the accuracy of SeaVision measurements and its performance in sea states up to $4.2 \mathrm{~m}$ in significant wave height and $10 \mathrm{~s}$ in mean period. There is no obvious difference in the distribution of points for the SpotterSeaVision in range 0.8 - $3 \mathrm{~m}$ of wave heights. SeaVision has a tendency (relatively to buoy) to overestimate mean period. WW3 model mostly underestimates wave heights and periods. 
(a)

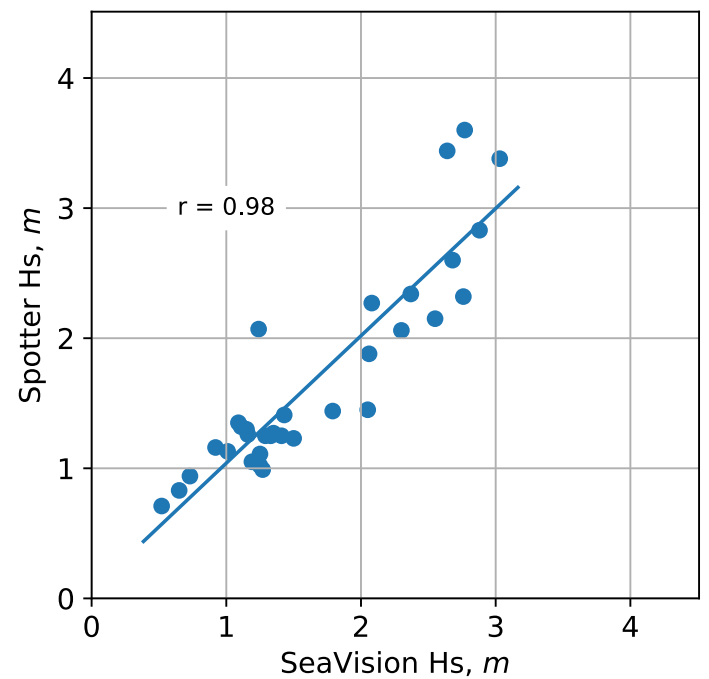

(c)

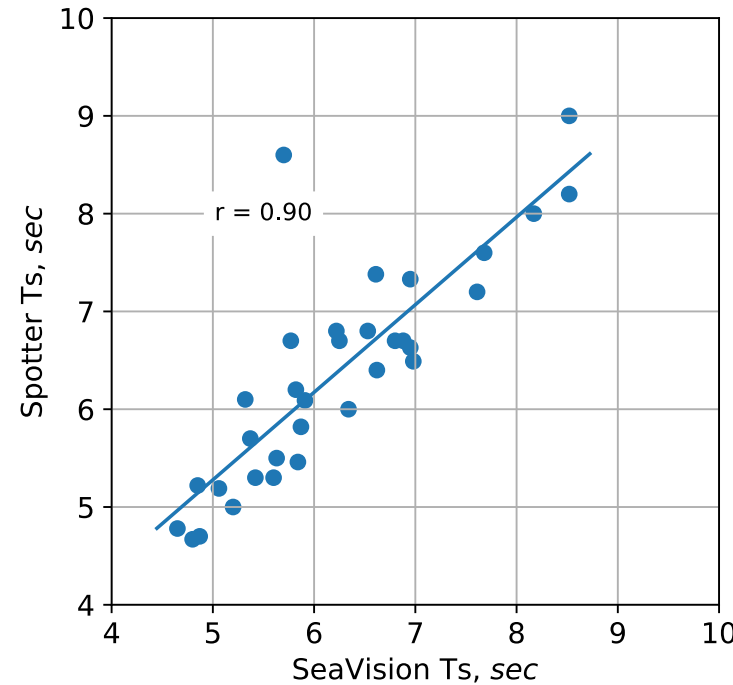

(b)

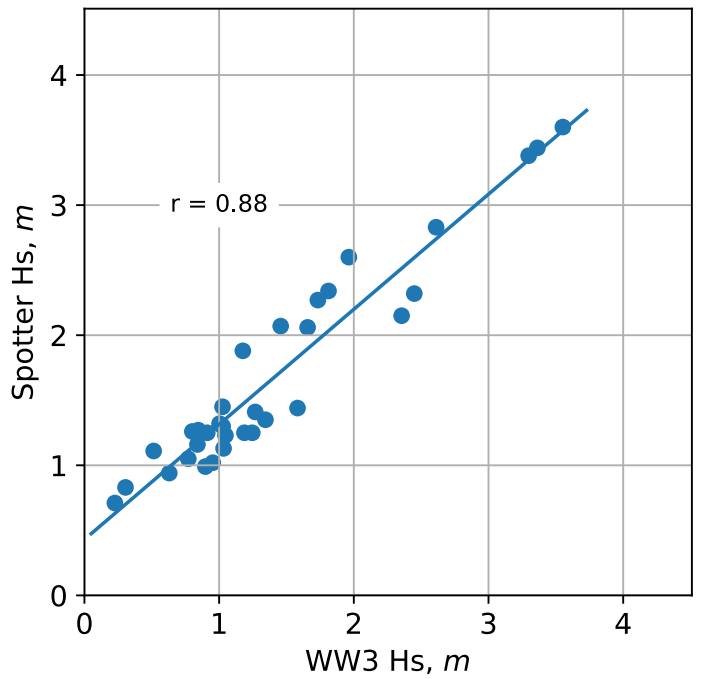

(d)

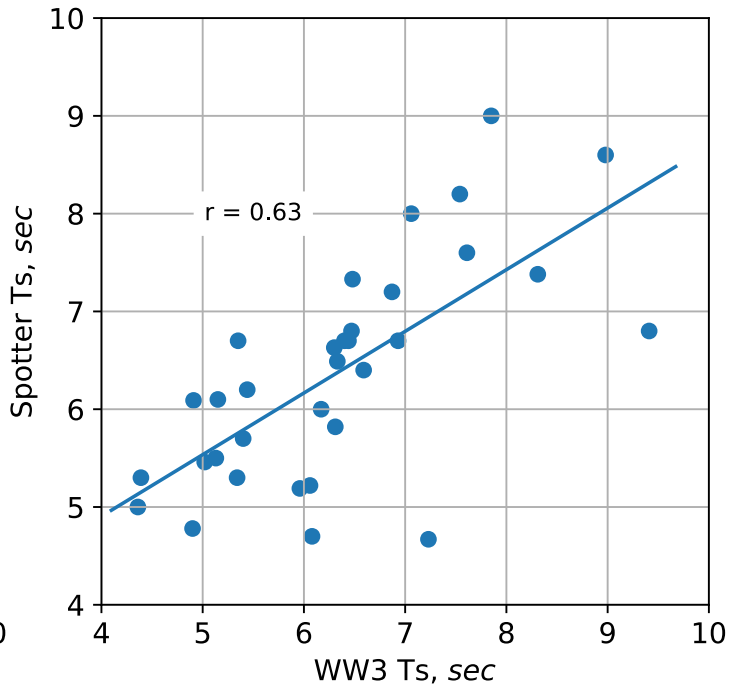

Figure 6: Scatterplots of the significant wave height $\left(H_{s}\right)$ and wave period $\left(T_{s}\right)$ estimates between SeaVision and Spotter $(a, c)$ and between WW3 and Spotter $(b, d)$ for all stations together with regression coefficients $r$.

Estimates of the $\mathrm{H}_{\mathrm{s}}$ from directional spectra are shown in Figure 7 for six stations (see Table A1). It is important to notice that all three sources of the data: SeaVision, Spotter buoy and WW3 demonstrate higher agreement in estimates of the waves direction (from) than in $\mathrm{H}_{\mathrm{s}}$ or $\mathrm{T}_{\mathrm{s}}$. The difference in waves direction doesn't exceed $10^{\circ}$. 


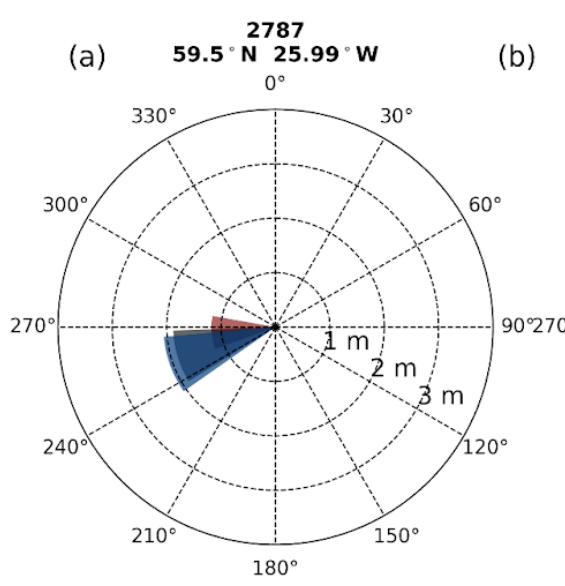

(d)

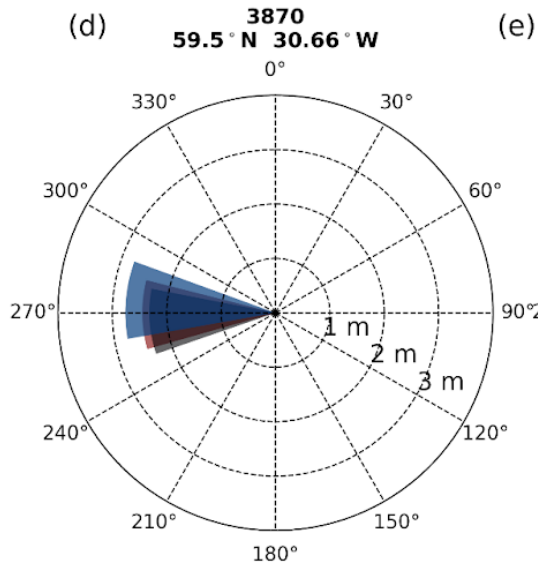

(b)

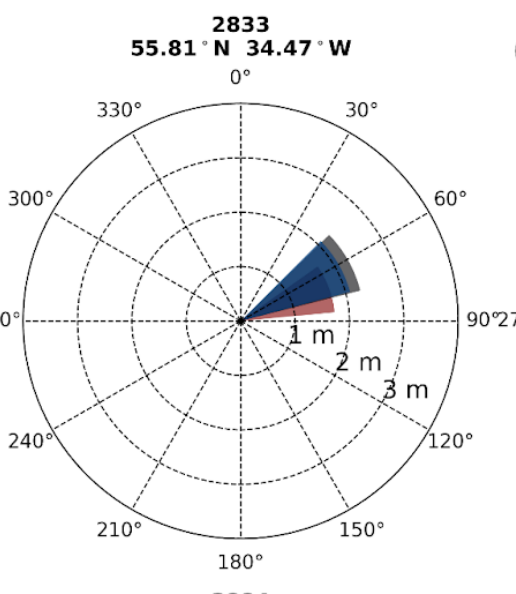

(e)

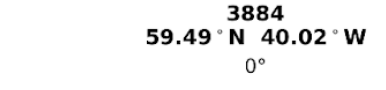

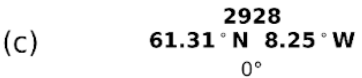

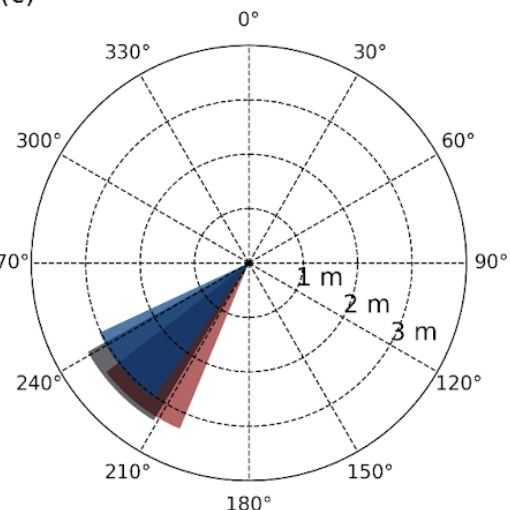

(f)
SeaVision Spotter WW3

Figure 7: Diagrams (roses) of wave direction (from) and $H_{s}$ on the basis of the three data sources: SeaVision (blue), Spotter (gray) and WW3 (red) at the stations: \#2787, \#2833, \#2928, \#3870, \#3884, \#3899 (see Table A1).

\section{Conclusions}

In this study we present the dataset of the observations of the wind waves collected during three research cruises (two in the North Atlantic and on in the Arctic) on the basis of usage navigational X-band marine radar and wave buoy Spotter. Nowadays there is still exists gap in the in situ observational network for the wind waves, at the same time winds waves is crucially important dynamical component of the interaction between the ocean and the atmosphere and play important role into the climate system. We also present a newly developed SeaVision system for digitizing and recording of the analogous marine radar signal and further analysis of the data to obtain wind waves' parameters such as significant wave height, wave period and wave energy spectra. The potential usage of the dataset is validation of the satellite missions and outputs from the models. 
We demonstrate an overall agreement of the estimates of significant wave height and wave period on the basis of SeaVision

with the same estimates simultaneously measured by the wave buoy Spotter and modelled by WW3 spectral wave model. At the same time estimates of the significant wave height between WW3, Spotter and SeaVision are in a better agreement than estimates of the wave period. Within the $\mathrm{H}_{\mathrm{s}}$ up to $4.2 \mathrm{~m}$ and $\mathrm{T}_{\mathrm{s}}$ up to $10 \mathrm{~s}$ the average difference between SeaVision and Spotter buoy is $3 \mathrm{~cm}$ for $\mathrm{H}_{\mathrm{s}}$, while for the Spotter minus WW3 this difference is $27 \mathrm{~cm}$. SeaVision has a tendency (relatively to Spotter) to overestimate mean period by $0.5 \mathrm{~s}$ while WW3 both overestimate and underestimate wave periods by up to $2,5 \mathrm{~s}$ (regression coefficient with Spotter is only 0.63 , Fig. 6). The best agreement among three sources of the data is in estimation of wave directions (Fig. 7), the difference doesn't exceed $10^{\circ}$.

It is important to notice while this paper describes the first results and prime data obtained with SeaVision, the commercial oceanographic systems for the wind waves monitoring such as WaMoS II (http://www.oceanwaves.de), SeaDarQ (http://www.seadarq.com/) and WaveFinder (Park et al., 2006) already exist and successfully operating and providing with

295 wind waves and currents observations. However, our main aim is to develop in the nearest future a low cost, independently operating and stable system that would allow to broaden observational network for the wind waves. Given that all ships navigating into the open ocean are equipped with navigational marine radar the in situ observational network for the wind waves can be potentially broaden by installing the low cost and independently operating version of the SeaVision (or any other system) to the Voluntary Observing Ships or to the any ship that would be willing to participate in the wind waves data collection in the open ocean.

\section{Data availability}

305 Dataset that contains significant wave height, wave period, wave energy frequency spectrum from both SeaVision and Spotter buoy at the locations of every station (Table A1) is available through the temporary link (https://sail.ocean.ru/tilinina2021/) while supporting dataset (Tilinina et al., 2021) is in technical processing at PANGAEA repository. Users interested in the analysis of the raw radar dataset are welcome to request access from Alexander Gavrikov (gavr@sail.msk.ru).

\section{Appendix A: List of the locations (stations) of the wind waves measurements during three research cruises}

Table A1: Stations list: geographical locations and time of all stations where the wind waves measurements were performed simultaneously with SeaVision and Spotter buoy.

\begin{tabular}{|l|l|l|l|l|l|l|}
\hline$\#$ & Station \# & $\begin{array}{l}\text { Start } \\
\text { UTC time }\end{array}$ & $\begin{array}{l}\text { End } \\
\text { UTC time }\end{array}$ & Latitude $^{\circ} \mathrm{N}$ & Longitude $^{\circ}$ E & Cruise \# \\
\hline
\end{tabular}




\begin{tabular}{|c|c|c|c|c|c|c|}
\hline 1 & 2868 & $27.08 .202013: 53$ & $27.08 .202014: 13$ & 65.67 & -25.26 & ASV50 \\
\hline 2 & 2881 & $28.08 .202010: 45$ & $28.08 .202011: 05$ & 66.49 & -28.89 & ASV50 \\
\hline 3 & 2885 & 28.08.2020 19:05 & $28.08 .202019: 25$ & 66.84 & -30.43 & ASV50 \\
\hline 4 & 2763 & $11.08 .202011: 25$ & $11.08 .202011: 45$ & 59.50 & -10.00 & ASV50 \\
\hline 5 & 2771 & $12.08 .202017: 00$ & $12.08 .202017: 20$ & 59.50 & -15.33 & ASV50 \\
\hline 6 & 2777 & $13.08 .202018: 15$ & $13.08 .202018: 35$ & 59.50 & -19.32 & ASV50 \\
\hline 7 & 2782 & 14.08.2020 18:42 & $14.08 .202019: 02$ & 59.50 & -22.66 & ASV50 \\
\hline 8 & 2787 & 15.08.2020 18:10 & $15.08 .202018: 30$ & 59.50 & -25.99 & ASV50 \\
\hline 9 & 2792 & 16.08.2020 14:45 & $16.08 .202015: 05$ & 59.50 & -29.33 & ASV50 \\
\hline 10 & 2797 & 17.08.2020 10:12 & $17.08 .202010: 32$ & 59.50 & -32.67 & ASV50 \\
\hline 11 & 2803 & $18.08 .202012: 17$ & $18.08 .202012: 37$ & 59.50 & -36.67 & ASV50 \\
\hline 12 & 2809 & $19.08 .202013: 26$ & $19.08 .202013: 46$ & 59.50 & -40.34 & ASV50 \\
\hline 13 & 2821 & 20.08.2020 13:44 & $20.08 .202014: 04$ & 59.90 & -42.32 & ASV50 \\
\hline 14 & 2833 & $22.08 .202015: 26$ & $22.08 .202015: 46$ & 55.81 & -34.47 & ASV50 \\
\hline 15 & 2841 & 23.08.2020 12:31 & 23.08.2020 12:51 & 56.78 & -33.53 & ASV50 \\
\hline
\end{tabular}




\begin{tabular}{|c|c|c|c|c|c|c|}
\hline 16 & 2849 & $24.08 .202014: 06$ & $24.08 .202014: 26$ & 58.53 & -31.43 & ASV50 \\
\hline 17 & 2856 & $25.08 .202012: 42$ & 25.08.2020 13:02 & 60.30 & -29.04 & ASV50 \\
\hline 18 & 2863 & $26.08 .202011: 45$ & 26.08.2020 12:05 & 62.40 & -25.73 & ASV50 \\
\hline 19 & 2901 & $30.08 .202013: 05$ & $30.08 .202013: 25$ & 65.94 & -26.49 & ASV50 \\
\hline 20 & 2903 & 01.09.2020 13:05 & 01.09.2020 13:25 & 64.82 & -12.49 & ASV50 \\
\hline 21 & 2928 & 03.09.2020 19:24 & $03.09 .202019: 44$ & 61.31 & -8.25 & ASV50 \\
\hline 22 & 2937 & 04.09.2020 21:16 & 04.09 .2020 21:36 & 59.50 & -9.31 & ASV50 \\
\hline 23 & 3831 & 29.06.2021 19:49 & 29.06.2021 20:09 & 59.50 & -4.60 & AI57 \\
\hline 24 & 3836 & $30.06 .202112: 50$ & $30.06 .2021 \quad 13: 10$ & 59.50 & -8.00 & AI57 \\
\hline 25 & 3841 & 01.07.2021 09:26 & 01.07.2021 09:46 & 59.49 & -11.33 & AI57 \\
\hline 26 & 3847 & 02.07.2021 10:33 & $02.07 .2021 \quad 10: 53$ & 59.50 & -15.33 & AI57 \\
\hline 27 & 3853 & 03.07.2021 $12: 35$ & 03.07.2021 12:55 & 59.50 & -19.33 & AI57 \\
\hline 28 & 3858 & 04.07.2021 11:38 & $04.07 .202111: 58$ & 59.50 & -22.67 & AI57 \\
\hline 29 & 3863 & 05.07.2021 10:05 & $05.07 .202110: 25$ & 59.50 & -26.00 & AI57 \\
\hline 30 & 3870 & $06.07 .2021 \quad 16: 29$ & 06.07.2021 $16: 49$ & 59.50 & -30.67 & AI57 \\
\hline
\end{tabular}




\begin{tabular}{|c|c|c|c|c|c|c|}
\hline 31 & 3875 & 07.07.2021 15:57 & 07.07.2021 16:17 & 59.52 & -33.98 & AI57 \\
\hline 32 & 3880 & 08.07.2021 17:32 & 08.07.2021 17:52 & 59.50 & -37.33 & AI57 \\
\hline 33 & 3884 & 09.07.2021 13:51 & 09.07.2021 14:11 & 59.50 & -40.00 & AI57 \\
\hline 34 & 3899 & $11.07 .202112: 45$ & 11.07.2021 13:05 & 59.90 & -42.48 & AI57 \\
\hline 35 & 3911 & 12.08 .2021 13:27 & $12.08 .202113: 47$ & 70.37 & 58.04 & AI58 \\
\hline 36 & 3929 & 14.08.2021 21:43 & 14.08.2021 22:03 & 75.15 & 75.09 & AI58 \\
\hline 37 & 3930 & 15.08.2021 06:40 & 15.08.2021 07:00 & 73.98 & 72.66 & AI58 \\
\hline 38 & 3939 & $16.08 .2021 \quad 12: 40$ & 16.08.2021 13:00 & 73.75 & 73.66 & AI58 \\
\hline 39 & 3946 & $17.08 .202104: 53$ & 17.08.2021 05:13 & 73.31 & 79.35 & AI58 \\
\hline 40 & 3956 & 18.08 .2021 12:52 & 18.08.2021 13:12 & 75.14 & 79.54 & AI58 \\
\hline 41 & 3972 & 21.08 .2021 12:27 & 21.08.2021 12:47 & 82.14 & 78.88 & AI58 \\
\hline 42 & 3982 & 22.08 .2021 15:48 & 22.08.2021 16:08 & 81.93 & 73.70 & AI58 \\
\hline 43 & 3990 & 23.08.2021 14:43 & 23.08.2021 15:03 & 81.44 & 67.25 & AI58 \\
\hline 44 & 3997 & 24.08.2021 08:02 & 24.08.2021 08:22 & 81.04 & 72.66 & AI58 \\
\hline 45 & 4013 & 25.08.2021 19:28 & 25.08.2021 19:48 & 79.93 & 72.11 & AI58 \\
\hline
\end{tabular}




\begin{tabular}{|c|c|c|c|c|c|c|}
\hline 46 & 4020 & 26.08.2021 13:20 & $26.08 .2021 \quad 13: 40$ & 79.51 & 65.06 & AI58 \\
\hline 47 & 4025 & 27.08.2021 03:05 & $27.08 .202103: 25$ & 78.28 & 65.33 & AI58 \\
\hline 48 & 4029 & 27.08 .2021 12:39 & $27.08 .202112: 59$ & 77.67 & 65.45 & AI58 \\
\hline 49 & 4031 & 27.08.2021 18:30 & $27.08 .202118: 50$ & 77.86 & 64.85 & AI58 \\
\hline 50 & 4040 & 28.08.2021 11:11 & 28.08.2021 11:31 & 78.84 & 61.62 & AI58 \\
\hline
\end{tabular}

\section{Author contributions}

NT, AG, DI, VS, AS, LS, VS and PS participated in research cruises and data collection. The leading role in field work program development and implementation belongs to AG and VS. DI made preprocessing, postprocessing and analysis of the radar (SeaVision) dataset, VS developed configuration and run WW3 model for the period of cruises, AG analysed all Spotter buoy data. VF, BT and SB provided hardware development and mounting of the SeaVision to the research vessels. NT has a leading role in the project set up and manuscript writing. The initial idea of the research belongs to SG. All authors contributed to the discussion, interpretation of the results and writing.

\section{Competing interests}

The authors declare no conflict of interests.

\section{Acknowledgements}

We acknowledge the Atlantic branch of the Shirshov Institute of Oceanology in Kaliningrad for their local support and crew of research vessels Akademik Sergey Vavilov and Akademic Ioffe for their help in setting up buoy measurements in the open ocean. We are also thankful to Mikhail Krinitsky, Viktoriya Grigorieva and Igor Goncharenko from Shirshov Institute of Oceanology (SIO) for their help with setting up hardware for radar signal digitization and useful advices.

\section{Financial support}


This study was funded by the Russian Foundation for Basic Research, project № 20-35-70025. VS ang AG were also supported with grant № 17-77-20112-P from Russian Science Foundation (WW3 setting for the period of the research cruises). SG was supported by the Ministry of Science and Higher Education of the Russian Federation (agreement 075-15-2021-577, interpretation and analysis of observational biases).

\section{References}

Borge, J. C. N., Reichert, K. and Dittmer, J.: Use of nautical radar as a wave monitoring instrument, Coastal Engineering, 345 37(3-4), https://doi.org/10.1016/S0378-3839(99)00032-0,1999.

Buckley, J. R. and Aler, J.: Estimation of ocean wave height from grazing incidence microwave backscatter, in International Geoscience and Remote Sensing Symposium (IGARSS),vol. 2., https://doi.org/10.1109/IGARSS.1997.615328, 1997.

350 Buckley, J. R. and Aler, J.: Enhancements in the determination of ocean surface wave height from grazing incidence microwave backscatter, in International Geoscience and Remote Sensing Symposium (IGARSS), vol.5.,https://doi.org/10.1109/IGARSS.1998.702254, 1998.

Campana, J., Terrill, E. J. and Paolo, T. de: A new inversion method to obtain upper-ocean current-depth profiles using Xband observations of deep-water waves, Journal of Atmospheric and Oceanic Technology, 34(5), https://doi.org/10.1175/JTECH-D-16-0120.1, 2017.

Cavaleri, L., Barbariol, F. and Benetazzo, A.: Wind-wave modeling: Where we are, where to go, Journal of Marine Science and Engineering, 8(4), https://doi.org/10.3390/JMSE8040260, 2020.

Chen, Z., He, Y., Zhang, B., \& Qiu, Z. (2015). Determination of nearshore sea surface wind vector from marine X-band radar images. Ocean Engineering, 96, 79-85,https://doi.org/10.1016/J.OCEANENG.2014.12.019, 2015.

Chen, Z., Zhang, B., Kudryavtsev, V., He, Y., \& Chu, X. (2019). Estimation of sea surface current from X-band marine radar

images by cross-spectrum analysis. Remote Sensing, 11(9), https://doi.org/10.3390/rs11091031, 2019.

Crombie, D. D.: Doppler spectrum of sea echo at 13.56 Mc./s. [3], Nature, 175(4459), https://doi.org/10.1038/175681a0, 1955.

Dankert, H., Horstmann, J. and Rosenthal, W.: Ocean wind fields retrieved from radar-image sequences, Journal of

Geophysical Research: Oceans, 108(11), https://doi.org/10.1029/2003jc002056, 2003.

Dankert, H. and Horstmann, J.: A marine radar wind sensor, Journal of Atmospheric and Oceanic Technology, 24(9), https://doi.org/10.1175/JTECH2083.1, 2007.

375 Derkani, M. H., Alberello, A., Nelli, F., Bennetts, L. G., Hessner, K. G., Machutchon, K., Reichert, K., Aouf, L., Khan, S. and Toffoli, A.: Wind, waves, and surface currents in the Southern Ocean: Observations from the Antarctic Circumnavigation Expedition, Earth System Science Data, 13(3), https://doi.org/10.5194/essd-13-1189-2021, 2021. 
https://doi.org/10.5194/essd-2021-431

Preprint. Discussion started: 16 December 2021

(c) Author(s) 2021. CC BY 4.0 License.

Drazen, D., Terrill, E., Walker, D., Hazard, J., Cook, T. and Scott, S.: Full-scale measurements of wave impact loading on a flat plate, in Proceedings of the International Conference on Offshore Mechanics and Arctic Engineering - OMAE, vol. 1, Rio de Janeiro, Brazil, 1-6 July 2012, OMAE2012-83608, https://doi.org/10.1115/OMAE2012-83608, 2012.

Drouet, C., Cellier, N., Raymond, J. and Martigny, D.: Sea state estimation based on ship motions measurements and data fusion, in Proceedings of the International Conference on Offshore Mechanics and Arctic Engineering - OMAE, vol. 5., Nantes, France, 9-14 June 2013, OMAE2013-10657, https://doi.org/10.1115/OMAE2013-10657, 2013.

Rogers, W. E., Babanin, A. V. and Wang, D. W.: Observation-consistent input and whitecapping dissipation in a model for wind-generated surface waves: Description and simple calculations, Journal of Atmospheric and Oceanic Technology, 29(9), https://doi.org/10.1175/JTECH-D-11-00092.1, 2012.

Falina, A., Sokov, A., \& Sarafanov, A.: Variability and renewal of Labrador Sea Water in the Irminger basin in 1991-2004. Journal of Geophysical Research, 112, C01006. https://doi.org/10.1029/2005JC003348, 2007.

Fujii, S., Heron, M. L., Kim, K., Lai, J. W., Lee, S. H., Wu, X., Wu, X., Wyatt, L. R. and Yang, W. C.: An overview of developments and applications of oceanographic radar networks in Asia and Oceania countries, Ocean Science Journal, 48(1), https://doi.org/10.1007/s12601-013-0007-0, 2013.

Gangeskar, R.: Adaptive method for estimation of wave height based on statistics of sea surface images, in International Geoscience and Remote Sensing Symposium (IGARSS), vol. 1., https://doi.org/10.1109/IGARSS.2000.860484, 2000.

Gangeskar, R.: Wave height derived by texture analysis of X-band radar sea surface images, in International Geoscience and Remote Sensing Symposium (IGARSS), vol. 7., https://doi.org/10.1109/IGARSS.2000.860301, 2000.

Gavrikov, A., Gulev, S. K., Markina, M., Tilinina, N., Verezemskaya, P., Barnier, B., Dufour, A., Zolina, O., Zyulyaeva, Y., 405 Krinitskiy, M., Okhlopkov, I. and Sokov, A.: RAS-NAAD: 40-yr high-resolution north atlantic atmospheric hindcast for multipurpose applications (new dataset for the regional mesoscale studies in the atmosphere and the ocean), Journal of Applied Meteorology and Climatology, 59(5), https://doi.org/10.1175/JAMC-D-19-0190.1, 2020.

Gladyshev, S. V., Gladyshev, V. S., Gulev, S. K., \& Sokov, A. V.: Structure and variability of the meridional overturning 410 circulation in the North Atlantic subpolar gyre, 2007-2017. Doklady Earth Sciences, 483(2), 1524-1527. https://doi.org/10.1134/S1028334X18120024, 2018.

Gladyshev, S. V., Gladyshev, V. S., Klyuvitkin, A. A., \& Gulev, S. K.: A new look at the water exchange between the arctic and the north Atlantic in the Iceland Basin. Doklady Earth Sciences, 485(2), 401-404. 415 https://doi.org/10.1134/S1028334X19040020, 2019.

Greenwood C., Vogler A., Morrison J., Murray A.: The approximation of a sea surface using a shore mounted X-band radar with low grazing angle. Remote Sensing of Environment, 204, 439-447, https://doi.org/10.1016/j.rse.2017.10.012, 2018.

420 Hasselmann, K.: Theory of synthetic aperture radar ocean imaging: a MARSEN view., Journal of Geophysical Research, 90(C3), https://doi.org/10.1029/JC090iC03p04659, 1985.

Hasselmann, K., Hasselmann, S., Bauer, E., Janssen, P. A. E. M., Komen, G. J., Bertotti, L., Lionello, P., Guillaume, A., Cardone, V. C., Greenwood, J. A., Reistad, M., Zambresky, L. and Ewing, J. A.: The WAM model - a third generation ocean 425 wave prediction model., J. PHYS. OCEANOGR., 18(12, Dec. 1988), https://doi.org/10.1175/15200485(1988)018<1775:TWMTGO>2.0.CO;2, 1988. 
https://doi.org/10.5194/essd-2021-431

Preprint. Discussion started: 16 December 2021

(c) Author(s) 2021. CC BY 4.0 License.

Hasselmann, S., Hasselmann, K., Allender, J. H. and Barnett, T. P.: Computations and parameterizations of the nonlinear energy transfer in a gravity-wave spectrum. Part II: parameterizations of the nonlinear energy transfer for application in wave models., J. PHYS. OCEANOGR., 15(11, Nov. 1985), $\quad$ https://doi.org/10.1175/15200485(1985)015<1369:CAPOTN>2.0.CO;2, 1985.

Hatten, H., Seemann, J., Horstmann, J. and Ziemer, F.: Azimuthal dependence of the radar cross section and the spectral background noise of a nautical radar at grazing incidence, in International Geoscience and Remote Sensing Symposium (IGARSS), vol. 5.,https://doi.org/10.1109/IGARSS.1998.702255,1998.

Hersbach, H., Bell, B., Berrisford, P., Hirahara, S., Horányi, A., Muñoz-Sabater, J., ... \& Thépaut, J. N.: The ERA5 global reanalysis, Quarterly Journal of the Royal Meteorological Society, 146(730), 1999-2049, https://doi.org/10.1002/qj.3803, 2010.

Hessner, K. and Hanson, J. L.: Extraction of coastal wavefield properties from X-band radar, in International Geoscience and Remote Sensing Symposium (IGARSS), https://doi.org/10.1109/IGARSS.2010.5650134, 2010.

Hessner, K., Wallbridge, S. and Dolphin, T.: Validation of areal wave and current measurements based on X-band radar, in 4452015 IEEE/OES 11th Current, Waves and Turbulence Measurement, CWTM 2015., https://doi.org/10.1109/CWTM.2015.7098102, 2015.

Hilmer, T. and Thornhill, E.: Observations of predictive skill for real-time Deterministic Sea Waves from the WaMoS II, in OCEANS 2015 - MTS/IEEE Washington., 2016.

450 Hwang, P. A., Sletten, M. A. and Toporkov, J. V.: A note on Doppler processing of coherent radar backscatter from the water surface: With application to ocean surface wave measurements, Journal of Geophysical Research: Oceans, 115(3), https://doi.org/10.1029/2009JC005870, 2010.

Izquierdo, P., Guedes Soares, C., Nieto-Borge, J. C. and Rodríguez, G. R.: A comparison of sea-state parameters from nautical radar images and buoy data, Ocean Engineering, 31(17-18), https://doi.org/10.1016/j.oceaneng.2004.04.004, 2004.

Johnson, J. T., Burkholder, R. J., Toporkov, J. V., Lyzenga, D. R. and Plant, W. J.: A numerical study of the retrieval of sea surface height profiles from low grazing angle radar data, in IEEE Transactions on Geoscience and Remote Sensing, vol. 47., https://doi.org/10.1109/IGARSS.2010.5650134, 2009.

Liu, Q., Rogers, W. E., Babanin, A. V., Young, I. R., Romero, L., Zieger, S., Qiao, F. and Guan, C.: Observation-based source terms in the third-generation wave model WAVEWATCH III: Updates and verification, Journal of Physical Oceanography, 49(2), https://doi.org/10.1175/JPO-D-18-0137.1, 2019.

465 Lund, B., Collins, C. O., Graber, H. C., Terrill, E. and Herbers, T. H. C.: Marine radar ocean wave retrieval's dependency on range and azimuth, in Ocean Dynamics, vol. 64., http://dx.doi.org/10.1007/s10236-014-0725-6, 2014.

Nagai, T., Satomi, S., Terada, Y., Kato, T., Nukada, K. and Kudaka, M.: GPS buoy and seabed installed wave gauge application to offshore tsunami observation, in Proceedings of the International Offshore and Polar Engineering Conference, vol. 2005.,

470 Seoul, Korea, 19-24 June 2005,ISOPE-I-05-282, available at: https://onepetro.org/ISOPEIOPEC/proceedingsabstract/ISOPE05/All-ISOPE05/ISOPE-I-05-282/9448, 2005.

Nieto-Borge, J. C. and Guedes Soares, C.: Analysis of directional wave fields using X-band navigation radar, Coastal Engineering, 40(4), https://doi.org/10.1016/S0378-3839(00)00019-3, 2000.

475 Nieto-Borge, J. C., Hessner, K., Jarabo-Amores, P. and De La Mata-Moya, D.: Signal-to-noise ratio analysis to estimate ocean wave heights from X-band marine radar image time series, IET Radar, Sonar and Navigation, 2(1), https://doi.org/10.1049/ietrsn:20070027, 2008. 
https://doi.org/10.5194/essd-2021-431

Preprint. Discussion started: 16 December 2021

(c) Author(s) 2021. CC BY 4.0 License.

Nieto-Borge, J. C., Jarabo-Amores, P., De La Mata-Moya, D. and López-Ferreras, F.: Estimation of ocean wave heights from 4-9 June 2006, 35 - 41, https://doi.org/10.1115/OMAE2006-92015, 2006.

Plant, W. J., Keller, W. C., Reeves, A. B., Uliana, E. A. and Johnson, J. W.: Airborne microwave doppler measurements of ocean wave directional spectra, International Journal of Remote Sensing, 8(3), https://doi.org/10.1080/01431168708948644, 1987.

Plant, W. J.: A model for microwave Doppler sea return at high incidence angles: Bragg scattering from bound, Tilted waves, Journal of Geophysical Research: Oceans, 102(C9), https://doi.org/10.1029/97JC01225, 1997.

490 Park, G. I., Choi, J. W., Kang, Y. T., Ha, M. K., Jang, H. S., Park, J. S., Kwon, S. H.

(2006). The application of marine X-band radar to measure wave condition during sea trial. Journal of Ship and Ocean Technology, 10(4), 34-48, available at: https://www.koreascience.or.kr/article/JAKO200614539116884.page, 2006.

Raghukumar, K., Chang, G., Spada, F., Jones, C., Janssen, T. and Gans, A.: Performance characteristics of “spotter," a newly 495 developed real-time wave measurement buoy, Journal of Atmospheric and Oceanic Technology, 36(6), https://doi.org/10.1175/JTECH-D-18-0151.1, 2019.

Reichert, K., Hessner, K., Dannenberg, J. and Traenkmann, I.: X-Band radar as a tool to determine spectral and single wave properties, in Proceedings of the International Conference on Offshore Mechanics and Arctic Engineering - OMAE, vol. 2006., Hamburg, Germany, 4-9 June 2006, 683-688, https://doi.org/10.1115/OMAE2006-92015, 2006.

Ribal, A. and Young, I. R.: Publisher Correction: 33 years of globally calibrated wave height and wind speed data based on altimeter observations (Scientific Data, (2019), 6, 1, (77), 10.1038/s41597-019-0083-9), Scientific Data, 6(1), https://doi.org/10.1038/s41597-019-0108-4, 2019.

Sarafanov, A., Falina, A., Sokov, A., \& Demidov, A.: Intense warming and salinification of intermediate waters of southern origin in the eastern subpolar North Atlantic in the 1990s to mid-2000s. Journal of Geophysical Research, 113(C12). https://doi. org/10.1029/2008JC004975, 2008.

510 Sarafanov, A., Falina, A., Sokov, A., Zapotylko, V., \& Gladyshev, S.: Ship-based monitoring of the northern north Atlantic Ocean by the Shirshov Institute of Oceanology. The main results. In Ship based monitoring of the northern North Atlantic ocean by the Shirshov Institute of Oceanology. The Ocean in Motion (pp. 415-427). Springer Oceanography. https://doi.org/10.1007/978-3-319-71934-4_25, 2018.

515 Seemann, J., Senet, C. M., Wolff, U. and Ziemer, F.: Nautical x-band radar image processing: Monitoring of morphodynamic processes in coastal waters, Oceans Conference Record (IEEE), 2, Providence, RI, USA,11-14 September 2000, 1329-1335, https://doi.org/10.1109/OCEANS.2000.881788, 2000.

Seemann, J., Ziemer, F. and Senet, C. M.: Method for computing calibrated ocean wave spectra from measurements with a 520 nautical X-band radar, in Oceans Conference Record (IEEE), vol. 2., Halifax, NS, Canada, 6-9 October 1997, https://doi.org/10.1109/OCEANS.1997.624154, 1997.

Senet, C. M., Seemann, J. and Ziemer, F.: The near-surface current velocity determined from image sequences of the sea surface, IEEE Transactions on Geoscience and Remote Sensing, 39(3), https://doi.org/10.1109/36.911108, 2001. 
https://doi.org/10.5194/essd-2021-431

Preprint. Discussion started: 16 December 2021

(c) Author(s) 2021. CC BY 4.0 License.

Senet, C. M., Seemann, J., Flampouris, S. and Ziemer, F.: Determination of bathymetric and current maps by the method DiSC based on the analysis of nautical X-band radar image sequences of the sea surface (November 2007), IEEE Transactions on Geoscience and Remote Sensing, 46(8), https://doi.org/10.1109/TGRS.2008.916474, 2008.

530 Shen, C., Huang, W., Gill, E. W., Carrasco, R. and Horstmann, J.: An algorithm for surface current retrieval from X-band marine radar images, Remote Sensing, 7(6), https://doi.org/10.3390/rs70607753, 2015.

Stepanova N.B.: The first scientific school within the educational program "Floating University of IO RAS", Journal of oceanological research, 46(1), 189-191, https://doi.org/10.29006/1564-2291.JOR-2018.46(1).19, 2019.

Story, W. R., Fu, T. C. and Hackett, E. E.: Radar measurement of ocean waves, in Proceedings of the International Conference on Offshore Mechanics and Arctic Engineering - OMAE, vol. 6., https://doi.org/10.1115/OMAE2011-49895, 2011.

Sverdrup, H. U. and Munk, W. H.: Wind, Sea, and Swell. Theory of Relations For Forecasting, Office, (601), available at: https://books.google.com/books?id=LxtSAQAAMAAJ\&printsec=frontcover\&hl=ru\&source=gbs ge summary $\mathrm{r} \&$ cad $=0 \# \mathrm{v}$ =onepage\&q\&f=false, 1947.

The WAVEWATCH III Development Group (WW3DG), (2019): User manual and system documentation of WAVEWATCH III R version 6.07. Tech. Note 333, NOAA/NWS/NCEP/MMAB, College Park, MD, USA, 465 pp. + Appendices., available at: https://github.com/NOAA-EMC/WW3/wiki/Manual, 2019.

Terrill, E. J.: X-band Observations of Waves, Algorithm Development, and Validation High Resolution Wave-Air-Sea Interaction DRI, ONR Annual Rept. 2009, available at:https://www.google.com/books/edition/X_band_Observations_of_Waves_Algorithm_D/tOauAQAACAAJ?hl=en, 2009.

Tilinina N., Ivonin D., Gavrikov A., Sharmar V., Gulev S., Suslov A., Fadeev V., Trofimov B., Bargman S., Salavatova L., Koshkina V., Shishkova P., Sokov A.: Wind waves in the North Atlantic and Arctic from ship navigational radar (SeaVision system) and wave buoy Spotter during three research cruises in 2020 and 2021, PANGAEA, 2021, in technical processing.

555 Swail,V., Jensen, R.E., Lee, B., Turton, J., Thomas, J., Gulev, S., Yelland, M., Etala, P., Meldrum, D., Birkemeier, W., Burnett B. and Warren G.: Wave Measurements, Needs and Developments for the Next Decade., available at: http://waveworkshop.org/11thWaves/Papers/Swail_etal_Wave\%20Measurements.pdf, 2010.

Verezemskaya, P., Barnier, B., Gulev, S. K., Gladyshev, S., Molines, J. M., Gladyshev, V., Lellouche, J. M. and Gavrikov, 560 A.: Assessing Eddying (1/12 $)$ Ocean Reanalysis GLORYS12 Using the 14-yr Instrumental Record From $59.5^{\circ} \mathrm{N}$ Section in the Atlantic, Journal of Geophysical Research: Oceans, 126(6), https://doi.org/10.1029/2020JC016317, 2021.

Vicen-Bueno, R., Horstmann, J., Terril, E., de Paolo, T. and Dannenberg, J.: Real-time ocean wind vector retrieval from marine radar image sequences acquired at grazing angle, Journal of Atmospheric and Oceanic Technology, 30(1), https://doi.org/10.1175/JTECH-D-12-00027.1, 2013.

Vicen-Bueno, R., Lido-Muela, C. and Nieto-Borge, J. C.: Estimate of significant wave height from noncoherent marine radar images by multilayer perceptrons, Eurasip Journal on Advances in Signal Processing, 2012(1), https://doi.org/10.1186/16876180-2012-84, 2012.

Vogelzang, J., Boogaard, K., Reichert, K. and Hessner, K.: Wave height measurements with navigation radar, International Archives of Photogrammetry and Remote Sensing, 33(B7), available at:https://www.researchgate.net/profile/JurVogelzang/publication/228406388_WAVE_HEIGHT_MEASUREMENTS_WITH_NAVIGATION_RADAR/links/02e7e53 ccf36acf893000000/WAVE-HEIGHT-MEASUREMENTS-WITH-NAVIGATION-RADAR.pdf, 2000. 
https://doi.org/10.5194/essd-2021-431

Preprint. Discussion started: 16 December 2021

(c) Author(s) 2021. CC BY 4.0 License.

(c) (1)

Wetzel, L. B.: Electromagnetic Scattering from the Sea at Low Grazing Angles, in Surface Waves and Fluxes.,https://doi.org/10.1007/978-94-009-0627-3 3,1990.

Young, I. R., Rosenthal, W. and Ziemer, F.: A three-dimensional analysis of marine radar images for the determination of 580 ocean wave directionality and surface currents., Journal of Geophysical Research, 90(C1), https://doi.org/10.1029/JC090iC01p01049, 1985.

Young, I. R. and Babanin, A. V.: Spectral distribution of energy dissipation of wind-generated waves due to dominant wave 585 breaking, Journal of Physical Oceanography, 36(3), https://doi.org/10.1175/JPO2859.1, 2006. 